\title{
Experimento para visualização das linhas de campo elétrico
}

\author{
Experiment to visualize the electric field lines \\ I. P. Moraes; R. Alves; E. R. P. de Novais* \\ Mestrado Nacional Profissional em Ensino de Física, Faculdade de Física, Instituto de Ciências Exatas, \\ UNIFESSPA, 68505-080, Marabá-PA, Brasil \\ *ericonovais@unifesspa.edu.br
}

(Recebido em 28 de fevereiro de 2019; aceito em 29 de julho de 2019)

O método experimental é sem dúvida uma metodologia de ensino eficiente no aprendizado. Porém, equipamentos didáticos, em geral, são caros para a realidade das escolas públicas brasileiras. Soma-se a isso, a carência de equipamentos capazes de demonstrar o fenômeno do campo elétrico, assim os professores de Física são obrigados a utilizar a abstração no ensino desse fenômeno. Com base nesse fato, o presente trabalho produziu um equipamento de baixo custo e fácil montagem para visualização das linhas de campo elétrico. Em seguida, aplicou-se o experimento em uma turma do Mestrado Nacional Profissional em Ensino de Física (MNPEP) polo UNIFESSPA, no qual todos os mestrados são professores dos níveis fundamental e médio. Assim, em uma análise qualitativa da turma, os mestrandos afirmaram compreender melhor o fenômeno e que este experimento de linhas de campo pode ser utilizado nas escolas de níveis fundamentais e médio. Palavras-chave: Equipamento didático, Campo elétrico, Linhas de campo elétrico.

The experimental method is undoubtedly an efficient teaching methodology in learning. However, teaching equipment, in general, are expensive to the reality of Brazilian public schools. Added to this, the lack of equipment to show the electric field phenomenon, so the physics teachers are required to use the abstraction in the teaching of this phenomenon. Based on this fact, the objective of the article is to demonstrate the manufacture of an experiment of low cost and easy assembly for visualization of the electric field lines. Then, the experiment was applied to a class of the National Professional Master in Physics Teaching (MNPEP) UNIFESSPA polo, in which all masters are elementary and high school teachers. Thus, in a qualitative analysis of the class, Master's students said better understand the phenomenon and that the field lines of experiment can be used in the basic and secondary levels of schools.

Keywords: Teaching equipment, Electric field, Electric field lines.

\section{INTRODUÇÃO}

A disciplina de Física é essencialmente experimental, contudo é muito prejudicada pela falta de equipamentos para reproduzir os fenômenos estudados de forma teórica em sala de aula. Assim, ainda por ser uma matéria que utiliza a Matemática como linguagem, este fato gera grande temor entre os estudantes. Dessa forma, a utilização de experimento possibilita ao estudante compreender a Física, não apenas como um aglomerado de fórmulas e demonstrações algébricas, mas como algo útil. Deste modo, torna-se evidente que a Física influencia na compreensão do mundo que nos cerca, fazendo com que o aluno se sinta mais à vontade com a disciplina. De acordo com Araújo e Abib (2003) [1]:

\begin{abstract}
A análise do papel das atividades experimentais desenvolvida amplamente nas últimas décadas revela que há uma variedade significativa de possibilidades e tendências de uso dessa estratégia de ensino de Física, de modo que essas atividades podem ser concebidas desde situações que focalizam a mera verificação de leis e teorias, até situações que privilegiam as condições para os alunos refletirem e reverem suas ideias a respeito dos fenômenos e conceitos abordados, podendo assim atingir um nível de aprendizado que lhes permita efetuar uma reestruturação de seus modelos explicativos dos fenômenos.
\end{abstract}

Deste modo, o método experimental torna a compreensão de alguns fenômenos físicos mais fáceis de serem compreendidos pelos estudantes, além de permitir ao estudante enxergar algumas características mais intrínsecas ao fenômeno [2, 3]. Paradoxalmente, tais equipamentos são, de forma geral, caros e de difícil acesso aos professores da rede pública. Deste modo, este trabalho 
possibilitará que o docente construa um aparelho capaz de demostrar a existência das linhas de campo elétrico com um custo relativamente baixo, implicando em uma aula mais dinâmica e de melhor assimilação do conteúdo pelos estudantes.

Não apenas o professor pode montar o equipamento, mas como a sua construção é simples e com componentes baratos e de fácil acesso, o docente poderá construir o equipamento com os estudantes, dessa forma poderá aproximar os discentes ao campo experimental $[4,5]$.

Portanto, o objetivo deste trabalho é mostrar o passo-a-passo da construção de um equipamento capaz de demostrar as linhas do campo elétrico.

\subsection{O CAMPO ELÉTRICO}

As primeiras observações dos efeitos do campo elétrico, segundo registros históricos, ocorreram no século VI A.C. O filósofo, matemático e astrônomo grego, Tales de Mileto, foi o primeiro a perceber esse fenômeno [5,6]. Ao atritar uma pedra, conhecida como âmbar, com um pedaço de lã, ele observou que a pedra atraía pequenos corpos [5,6]. Por não ter aplicações práticas o estudo do campo elétrico ficou restrito apenas a questões de entretenimento. Apenas no início do século XVII que um médico e profundo estudioso dos fenômenos elétricos e magnéticos, William Gilbert, publicou uma obra em que expunha as propriedades dos ímãs e descrevia experimentos sobre eletricidade estática $[6,7]$.

O jesuíta italiano Niccolo Cabeo pesquisou o trabalho de Gilbert e encontrou possíveis falhas, concluindo que as suas hipóteses estavam erradas em relação a origem do comportamento dos 'elétricos'. Sua grande contribuição foi a verificação de que quando certos objetos tocavam outros corpos eletrizados normalmente repeliam-se, contrariando a noção de "effluvium" proposta anteriormente por Gilbert [8].

O dinamarquês Oersted, quando era docente na Universidade Copenhague, descobriu os efeitos do eletromagnetismo. Oersted observou que uma corrente elétrica gerava um campo magnético ao redor de um fio. Ao percorrer o condutor, a corrente elétrica modificava a direção da agulha de uma bússola. Por outro lado, Faraday inverteu a experiência e verificou que ímãs quando aproximados de um condutor percorrido por corrente elétrica exerciam uma ação mecânica sobre este [8].

Ampère descobriu que dois fios retilíneos e paralelos eram atraídos se percorridos por corrente no mesmo sentido e repeliam se percorridos por correntes no sentido contrário. A partir de suas observações ele criou um experimento em que um fio enrolado em um tubo de vidro, o qual chamou de solenoide, ao ser percorrido por uma corrente elétrica, produzia o mesmo efeito de um ímã permanente [9]. Porém, foi Faraday o primeiro a propor o conceito de campo elétrico, a partir do modelo de linhas de força. Tal ideia surgiu inspirada no fenômeno das limalhas de ferro que quando são espalhadas sobre um ímã formam curvas ligando os dois polos [8].

As cargas elétricas geram campos elétricos esses campos são representados por vetores que chamamos de linhas de campo elétrico que entram e saem da carga ou da distribuição de cargas. Assim, de acordo com as linhas de campos proposto por Faraday temos diferentes distribuições de linhas de campo para distribuições distintas de cargas. Assim, na Figura 1 temos duas cargas, uma positiva e a outra negativa. As linhas de campo na carga positiva estão entrando como mostra a Figura 1a, enquanto na Figura 1b as linhas de campo estão saindo da carga negativa.

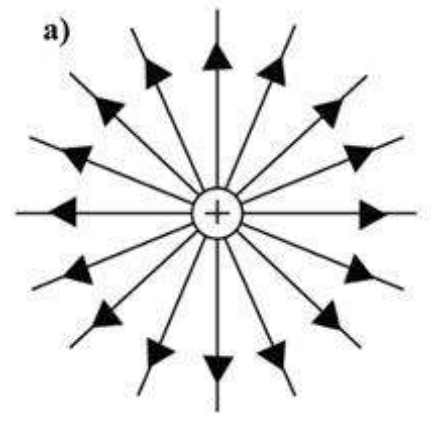

Carga Positiva

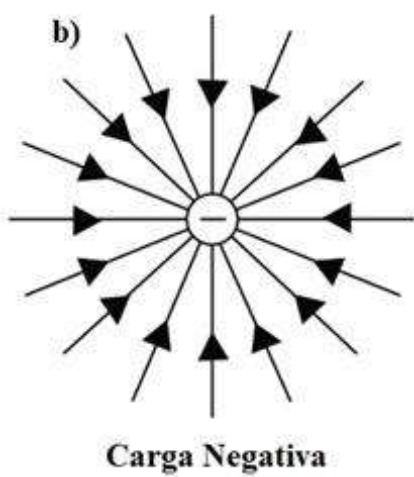

Carga Negativa

Figura 1: Representação vetorial das linhas de campo elétrico de uma carga pontual positiva e negativa. Fonte: Brasil Escola (2019) [14]. 
A Figura 2 mostra a distribuição das linhas de campos quando duas cargas distintas estão interagindo, observando-se que as linhas de campo nascem na carga positiva e morrem na negativa. Carl Friederich Gauss, importante matemático alemão, foi responsável por estabelecer uma relação direta entre a carga resultante envolvida por uma superfície fechada e o fluxo elétrico resultante de um campo elétrico através desta superfície, este é um método muito importante para calcular o valor do campo elétrico [3].

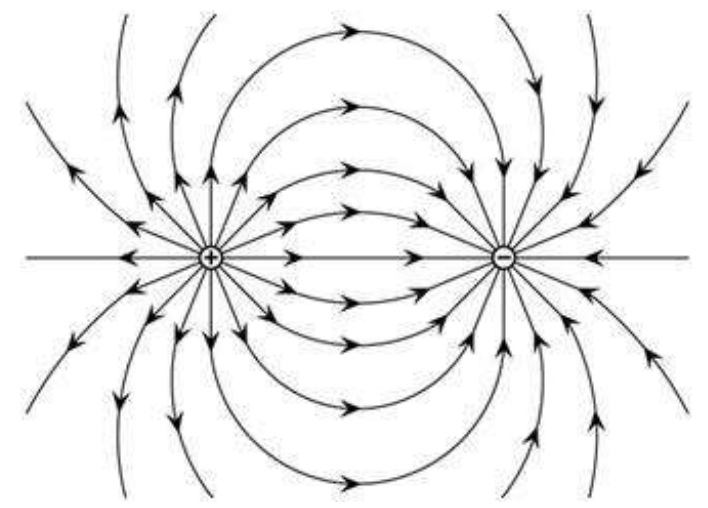

Figura 2: Representação vetorial do campo elétrico de duas cargas de sinais opostos quando estão interagindo. Fonte: Brasil Escola (2019) [14].

Podemos afirmar que cargas opostas se atraem enquanto cargas iguais se repelem como mostra a Figura 3. Observa-se a distribuição das linhas de campo para cargas elétricas com sinais iguais.

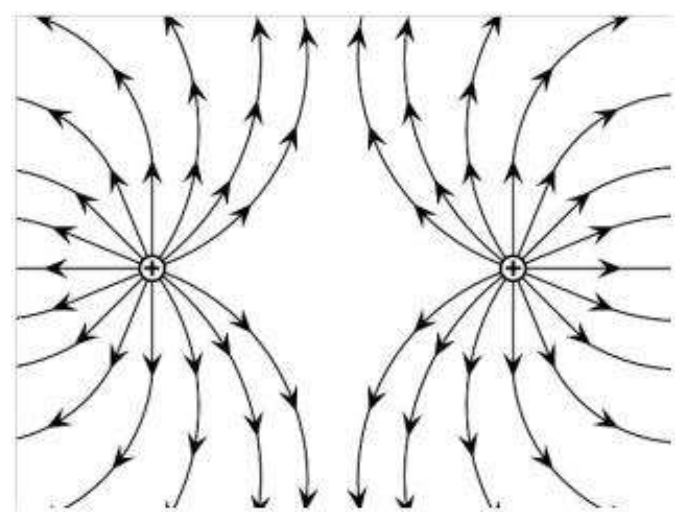

Figura 3: Representação vetorial do campo elétrico de duas cargas de mesmo sinal interagindo. Fonte: Brasil Escola (2019) [14].

Maxwell organizou matematicamente os conceitos de campo elétrico e magnético e como resultado culminou na teoria eletromagnética clássica. Além disso, com as suas equações foi possível unir duas áreas até então distinta da Física, o Eletromagnetismo e a Ótica [5].

\section{MATERIAL E MÉTODOS}

Nesta seção mostraremos os componentes para a fabricação do equipamento e uma explicação sobre o funcionamento dos componentes no equipamento. Os componentes são:

1- uma travessa de vidro,

2- uma fonte de $12 \mathrm{~V}$,

3- dois resistores,

4- um transistor,

5- duas porcas, ou dois cilindros metálicos pequenos,

6- um flyback,

7- um litro de óleo de soja, 
8- sementes de gergelim.

A Figura 4 mostra o flyback, um componente encontrado em televisores e monitores de tubo. Esse componente terá a função de aumentar a tensão em milhares de voltes, ou seja, o flyback é um transformador, onde o enrolamento primário será conectado ao ferrite e o secundário encontra-se internamente ao flyback.

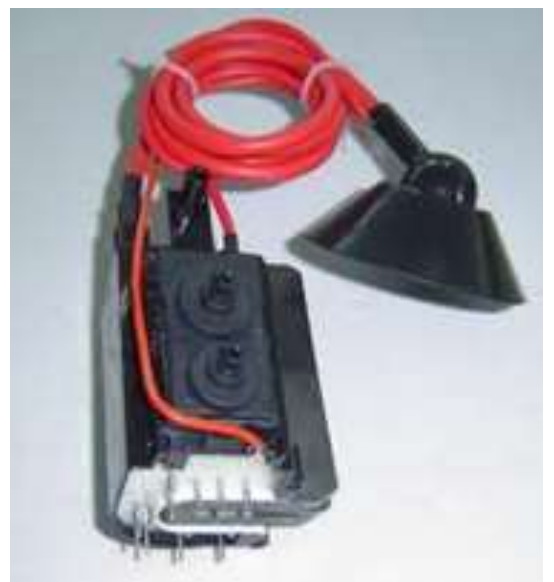

Figura 4. Componente Flyback. Fonte: Os autores.

Os resistores e o transistor formam um circuito integrado, que terá como função o oscilador do tipo Hartley $[11,12]$. Por uma questão de praticidade, o circuito oscilador foi montado em uma placa de circuito impresso como mostra a Figura 5.

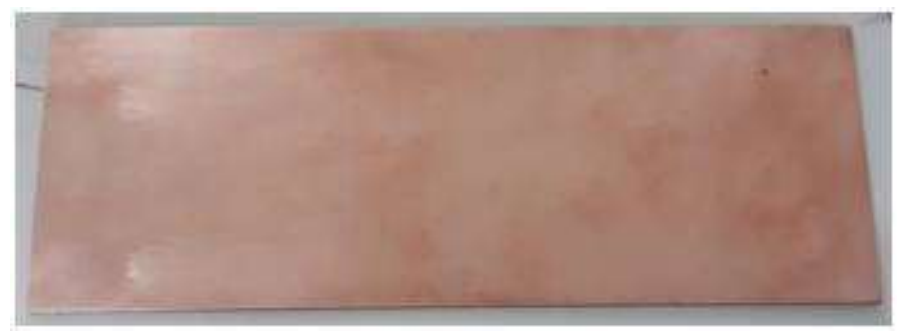

Figura 5: Placa de circuito impresso. Fonte: Os autores.

Resistores são componentes que têm a função de limitar a corrente elétrica, já transistores [10, 11] podem ser usados como amplificadores, reguladores de tensão, corrente ou como chave, sendo este o modo que será usado no experimento. O transistor possui 3 pinos coletor, emissor e base podendo ser usados com duas configurações, transistores NPN e PNP aqui utilizamos um transistor na configuração NPN.

Para o circuito oscilador, recomenda-se que a resistência $R_{1}$ seja de 20 a $30 \Omega$ e $R_{2}$ de 100 a 300 $\Omega$. Ambos os resistores devem ser de no mínimo $5 \mathrm{~W}$ de potência. Resistores de menor potência não suportarão a corrente e queimarão. Foram usados alguns transistores, no entanto, o que melhor respondeu a corrente de circulação foi o 2N3773. Recomenda-se acoplar um dissipador de calor, semelhante aos que são usados em processadores de computador, para minimizar o efeito Joule e aumento da vida útil do componente. O 2N3773 possui 2 pernas, base e emissor, o coletor é ligado na carcaça do transistor.

A placa de circuito impresso tem uma camada de cobre em sua superfície. Devido a isso, a superfície sofre oxidação, portanto, antes de desenhar sobre a placa deve-se limpar com esponja de lã de aço. Após a limpeza, desenha-se sobre a placa com um pincel marcador, preferencialmente de ponta fina, conforme mostra a Figura 6. 


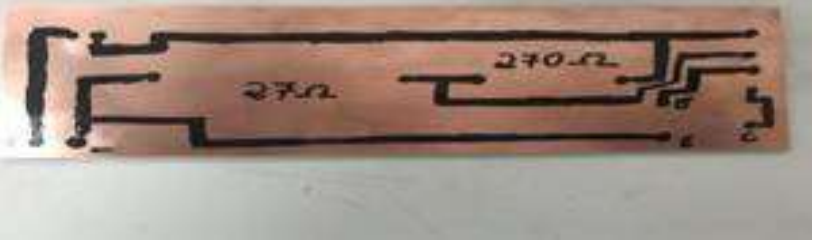

Figura 6: Placa de circuito impresso com as marcações das trilhas desenhadas com pincel. Fonte: Os autores.

Após realizações das marcações, a placa será colocada em uma solução de água e percloreto de ferro. Deste modo, esta solução reagirá com o cobre. Assim, o cobre será removido da placa e o circuito desenhado com pincel será mantido, como mostra a Figura 7. É recomendável utilizar uma alta concentração de percloreto de ferro para aumentar a velocidade de corrosão do cobre. Porém, deve-se tomar cuidado, pois, independente da concentração, se a placa repousar por muito tempo na solução, as trilhas marcadas com o pincel também serão corroídas. Por isso, deve-se monitorar a placa dentro da solução. Em seguida, realizamos os furos para soldagem dos componentes. Para soldar, usa-se fio de estanho e ferro de solda.

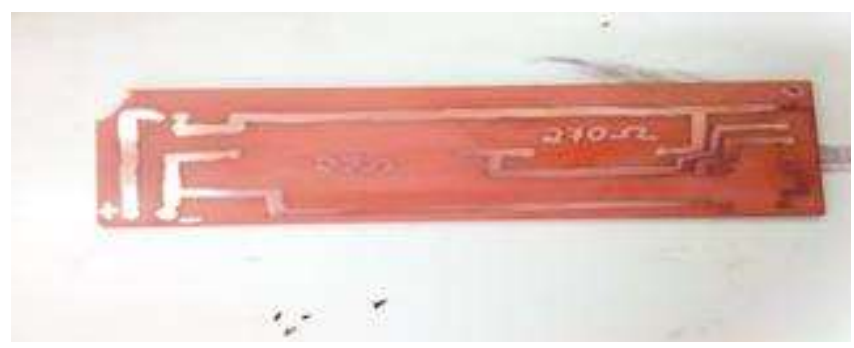

Figura 7: Placa de circuito após o processo de remoção do cobre da superfície. Fonte: Os autores.

Para o manuseio da solução, deve-se usar luvas para evitar contato direto. Apesar da solução ser ácida, não há um risco imediato caso entre em contato com a pele, mas, caso isso ocorra, deve-se lavar a região atingida com água corrente imediatamente.

A Figura 8 mostra esquematicamente como fica a ligação do circuito oscilador ligado ao flyback. Assim, recomendamos que a espira ligada a base do transistor tenha de 2 a 5 voltas. E a espira ligada ao coletor 12 a 18 voltas. As espiras ligadas ao flyback foram feitas com fios de cabo de rede, os quais possuem diâmetro adequado para enrolar no núcleo de ferrite, pois muitos flybacks têm o espaço pequeno entre o ferrite e o corpo do componente onde será feita a espira.

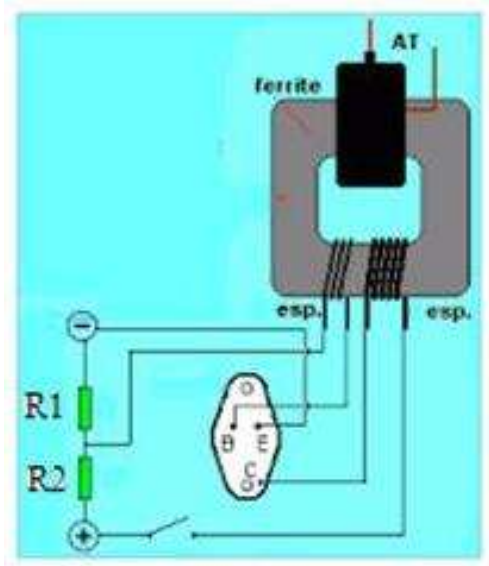

Figura 8: Oscilador do tipo Hartley conectado ao flyback. Fonte: Os autores.

Após ligar o circuito oscilador no flyback a diferença de tensão aplicada nas extremidades já estará elevada. Porém é necessário descobrir qual o pino que proporciona o maior potencial elétrico. 
Para isso, realizamos um teste prático, basta encostar um cabo de alta tensão, o cabo com o chapéu, e aproximar dos pinos. O pino que gera o maior potencial elétrico quebrará a rigidez do ar realizando uma descarga elétrica visível, a uma pequena distância. Desta forma, encontrado o pino da alta tensão, basta conectar o cabo de alta tensão a uma porca ou um pequeno cilindro metálico e ao pino que fornece o maior potencial elétrico. Porém, será necessário usar um cabo elétrico para realizar a ligação. As porcas ou cilindros serão colocados próximos um do outro dentro da travessa de vidro. Adiciona-se óleo de cozinha, que servirá como dielétrico, mas principalmente, para facilitar o deslocamento da semente, a qual indicará as linhas de campo (Figura 9).

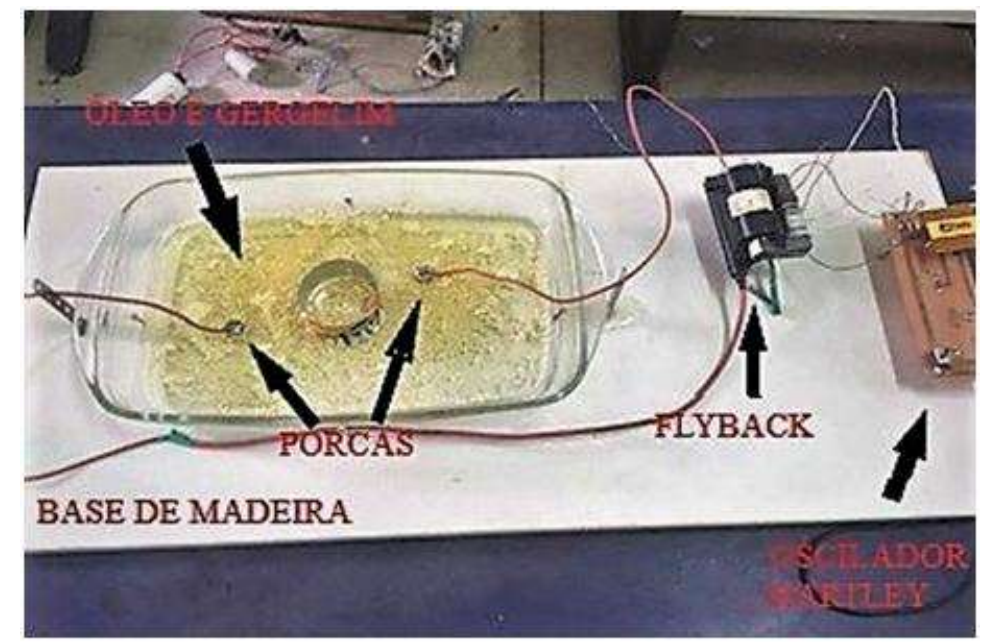

Figura 9: Experimento para visualização das linhas de campo elétrico. Fonte: Os autores.

Quando o circuito é alimentado a corrente percorrerá o resistor $R_{2}$ e saturará a base (B) do transistor. A base estando saturada, permitirá que a corrente flua do coletor (C) para o emissor (E), como mostra a Figura 8. Ao saturar a base a corrente que percorre a espira da esquerda gera um fluxo eletromagnético em um determinado sentido na espira da direita. A corrente que flui de coletor a emissor, quando o transistor estiver chaveado, gera um fluxo eletromagnético na espira da direita em sentido oposto ao da espira da esquerda. Assim, esse campo contrário faz com que a corrente na base diminua, ou seja, a base deixa de estar saturada, cortando o fluxo de coletor para emissor. Quando este corte ocorre, o fluxo eletromagnético da espira da direita cessa e a corrente flui novamente na espira da esquerda, saturando a base do transistor, chaveando novamente coletor para emissor. Esse processo ocorrerá indeterminadamente enquanto a fonte de alimentação estiver ligada.

O núcleo de ferrite do flyback é o responsável por transportar o fluxo eletromagnético para dentro deste, onde há espiras com grande número de enrolamentos, as quais elevarão a tensão oscilante de $12 \mathrm{~V}$ para milhares de Volts.

Deste modo, o experimento consiste de uma travessa de vidro, uma fonte de $12 \mathrm{~V}$, um circuito oscilador do tipo Hartley e um flyback. O circuito Hartley é responsável por fazer a tensão variar de $0 \mathrm{~V}$ a $12 \mathrm{~V}$ em alta frequência. Dois resistores são ligados para limitar a corrente, senão queimaria o transistor, o qual funcionará como uma chave. Dois terminais do flyback são ligados a duas porcas ou pequenos cilindros metálicos, e estas são inseridas dentro da travessa, na qual é adicionado o óleo e semente de gergelim, como mostra a Figura 9.

\section{RESULTADOS}

Assim, observando que o equipamento estava funcionando corretamente foi possível demonstrálo na disciplina Marcos no Desenvolvimento da Física no Mestrado Nacional Profissional em Ensino de Física. As Figuras 10 e 11 mostram o êxito na confecção do equipamento. Ao compararmos as Figuras 10 e $11 \mathrm{com}$ as Figuras 1, 2 e 3 teóricas podemos concluir que há uma boa concordância entre a parte experimental e teórica. Importante ressaltar que toda carga imersa em uma região onde há um campo elétrico, sobre ela surgirá uma força. No entanto, no caso estudado, 
foi utilizado semente de gergelim para visualizar estas linhas. A semente não possui carga elétrica descompensada, ou seja, segundo a teoria, não deveria surgir força. Porém, a semente é um aglomerado de átomos e esses átomos possuem elétrons e prótons. Esses elétrons e prótons possuem carga elétrica e a força é exercida nestas cargas.

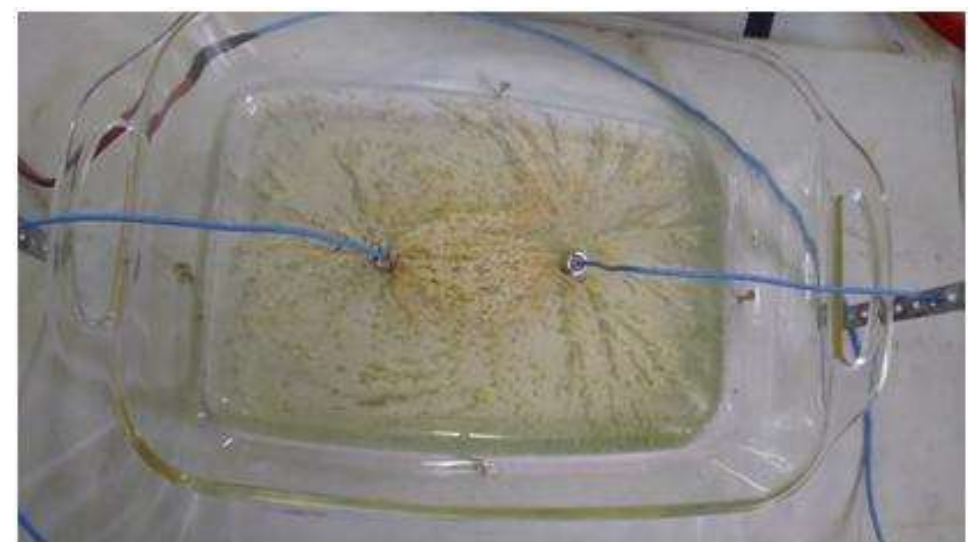

Figura 10: Formação das linhas de campo elétrico. Fonte: Os autores.

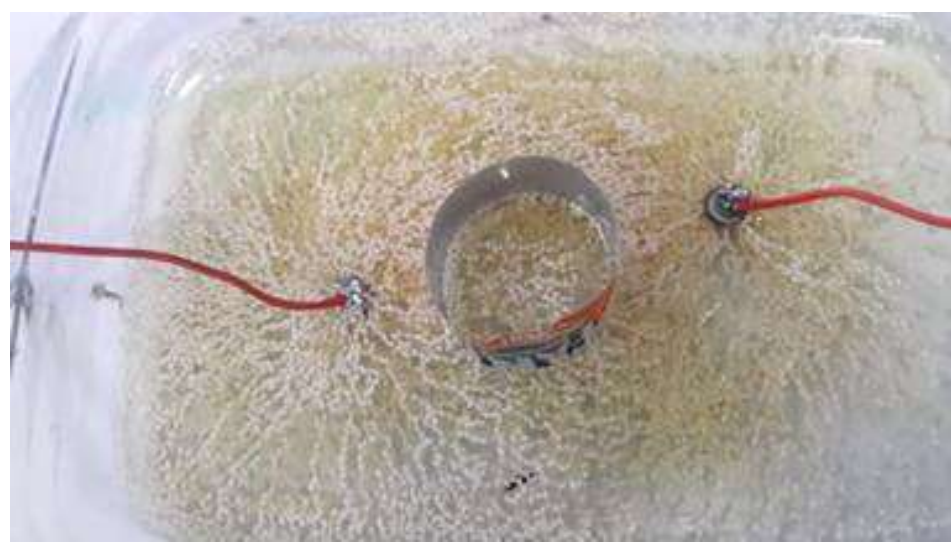

Figura 11: Formação das linhas de campo com blindagem eletrostática. Fonte: Os autores.

\section{CONCLUSÃO}

O conceito de linhas de campo elétrico é abstrato, tornando-se em muitos momentos difícil de ser ensinado, essa dificuldade é aumentada pela pouca opção de equipamentos que reproduzam o fenômeno. A partir das dificuldades apontadas, o presente trabalho produziu um equipamento com baixo custo e com montagem simples.

Após a produção do equipamento, foi realizada uma aula experimental com os mestrandos (professores de nível fundamental e médio) da turma de 2018 do programa MNPEF. Em seguida, foi realizada uma análise qualitativa na turma sobre a eficiência desse experimento, os resultados obtidos revelaram que os mestrandos conseguiram visualizar as linhas de campo e compreenderam melhor o fenômeno a partir da utilização do experimento.

Outra observação realizada pelos estudantes foi que, com a utilização do equipamento diminui as dificuldades de aplicação do experimento no ensino fundamental e médio.

Por fim, o presente trabalho revelou que o experimento para visualizar as linhas de campo elétrico pode ser produzido pelo professor ou pela turma, proporcionando o uso de metodologias diferenciadas para o processo ensino e aprendizagem.

\section{AGRADECIMENTOS}

A CAPES pelo suporte financeiro. 


\section{REFERÊNCIAS BIBLIOGRÁFICAS}

1. Araújo MST, Abib, MLVS. Atividades experimentais no ensino de Física: diferentes enfoques, diferentes finalidades. Rev Bras Ensino Física. 2003;25(2):176-194.

2. Reis EM, Silva OHM. Atividades experimentais: uma estratégia para o ensino da física. Cadernos Intersaberes. 2013;1(2):38-56.

3. Leiria TF, Mataruco SMC. O papel das atividades experimentais no processo ensino-aprendizagem de física. 2015. Disponível em: https://educere.bruc.com.br/arquivo/pdf2015/18234_8366.pdf

4. Santos GG, Souza DN. Experimentação real versus experimentação ideal no ensino de ciências e a prática do pensamento crítico. Scientia Plena. 2016;12(11). doi: 10.14808/sci.plena.2016.112716

5. Silva LHA, Zanon LB. A experimentação no ensino de ciências. p. 120-153. In: Schnetzler RP, Aragão RMR. Ensino de Ciências: Fundamentos e Abordagens. São Paulo, CAPES/UNIMEP, 2000.

6. Ortiz JPMT. Ensinando o conceito de campo elétrico a partir do fenômeno do raio. São Carlos: UFSCAR; 2016. 68 p.

7. Silva, OHM. A construção do conceito campo elétrico: da ciência física à física escolar. Curitiba: UFPR; 2006. $167 \mathrm{p}$.

8. Nussenzveig HM. Curso de física básica; São Paulo: Editora Edgard Blucher, 1997.

9. Halliday D, Resnick R, Krane KS. Física, 4ª ed., vol. 3, Rio de Janeiro: LTC, 1996.

10. Albuquerque, RO. Utilizando Eletrônica com AO, SCR, TRIAC, UJT, PUT, CI 555, LDR, LED, IGBT e FET de potência. São Paulo: Érica, 2010. 204 p.

11. Valadares, EC; Alves, EG; Chaves, AS. Aplicações da física quântica: do transistor à nanotecnologia. São Paulo: Ed. Livraria da Física; SBF, 2005. 90p.

12. Burian Jr. Y. Osciladores Eletrônicos. Editora Almeida Neves. Rio de Janeiro. 1972.

13. Mello, LFP. Projetos de fontes chaveadas: teoria e prática. 1. ed. São Paulo, SP: Érica, 2011. p. 288

14. Brasil Escola. O que é campo elétrico ?. Disponível em: https://brasilescola.uol.com.br/o-que-e/fisica/oque-e-campo-eletrico.htm. Acesso em 04 de agosto de 2019. 